\title{
Comments on "Does Paranormal Perception Occur in Near-Death Experiences?"
}

\author{
Bruce Greyson, M.D. \\ Department of Psychiatric Medicine, University of \\ Virginia
}

ABSTRACT: Keith Augustine's critique of studies of veridical perception in near-death experiences is based on unsubstantiated speculation from the popular media, rather than on supportive data or peer-reviewed literature. Nevertheless, addressing the issues he raises would improve the methodology of near-death research and strengthen the evidential database for veridical perception.

KEY WORDS: near-death experience; criticism; researcher bias; reliability; embellishment; veridical out-of-body perception.

Keith Augustine has done the field of near-death studies an invaluable service in raising questions about the quality and interpretation of evidence collected so far by near-death researchers. $\mathrm{He}$ points out weakness and ambiguities in the data and provides alternative explanations for findings that may have been overlooked by researchers. However, I believe that some of his assumptions are mistaken and that he has misconstrued the literature in some instances.

Augustine's assumption in his opening paragraph that "by all indications, the majority of near-death researchers have taken up

Bruce Greyson, M.D., is the Chester F. Carlson Professor of Psychiatry and Neurobehavioral Sciences and Director of the Division of Perceptual Studies at the University of Virginia. Reprint requests should be addressed to Dr. Greyson at the Division of Perceptual Studies, Department of Psychiatry and Neurobehavioral Sciences, University of Virginia Health System. P. O. Box 800152, Charlottesville, VA 22908-0152; e-mail: cbg4d@virginia.edu. 
near-death studies precisely because they believe that NDEs provide evidence for life after death" and later that "the majority of near-death researchers are interested in the subject because they believe that NDEs provide evidence for life after death" appears to be a confounding of scholarly near-death research with popular or New Age writings on the topic. The vast majority of near-death researchers are nurses, physicians, and other clinicians who focus on the impact of NDEs on their patients, but show little if any interest in the question of survival of death. Another significant group of near-death researchers are sociologists and anthropologists who focus on the role of NDE narratives in the collective mental life of human society, most of whom specifically disavow any interest in the survival question. Only a small minority of near-death researchers even address the possibility of postmortem survival, and few of those could be said to regard NDEs as proof of survival of bodily death. The vast literature on NDEs over the past three decades has focused on transformations in attitudes and values that are reported by NDErs and on speculations about physiological mechanisms possibly underlying the phenomenon. Much of what has been written about NDEs as evidence of an afterlife has in fact been written by critics of that position. This is not just my opinion: leading near-death researchers have almost unanimously noted the lack of interest in the survival question among their fellow researchers.

Raymond Moody, whom Augustine labeled "the 'founding father' of near-death studies," insisted that NDEs cannot provide evidence of survival. He wrote, "I have never equated - and I never meant to equate - my reporting of so-called 'near-death experiences' with a declaration on my part of the unquestioned existence of 'life after death"' (1999, p. 8). Kenneth Ring, the most prolific scholarly neardeath researcher, wrote that "we NDE researchers have been virtually unanimous in insisting that these experiences do not and cannot suggest the existence of an afterlife" (1990, p. 204).

Michael Grosso complained that "near-death research has not addressed the survival question. Near-death data have been treated phenomenologically or statistically analyzed for their relation to different variables. But researchers have not looked at data specifically with the survival hypothesis in mind" (1983, pp. 34-35). Emily Cook, Bruce Greyson, and Ian Stevenson wrote that "although reports of NDEs have proliferated during the past two decades, investigators of NDEs have with rare exceptions completely ignored the question of 
the survival of consciousness after the death of the body" (1998, p. 378).

Is this near-unanimous opinion based on objective data or is it commonly shared fallacy? In preparing this commentary, I reviewed all the articles and editorials that have been published in the Journal of Near-Death Studies and its predecessor Anabiosis, as exemplars of scholarly near-death research. I counted the number of articles that claimed or assumed NDEs provide evidence for survival, those that argued against that interpretation, and those that did not concern themselves with the survival question at all. To avoid inflating the number of articles against the survival interpretation, I did not count articles promoting purely physiological or psychological interpretations as being "against" the survival interpretation unless they specifically stated that NDEs do not provide evidence for survival. Of the 326 articles published in the quarter century of the Journal's history (Volumes 1-24), 25 (8 percent of the total) argued that NDEs provide evidence for survival, 15 (5 percent) argued that they do not, and 286 ( 88 percent) never addressed the question of postmortem survival. Thus more than 90 percent of the Journal's contributors found the question of survival either inconsistent with the evidence from NDEs or irrelevant to their interest in NDEs.

On what basis then did Augustine find that the majority of neardeath researchers had a vested interest in proving we survive death? Clearly Augustine is tilting at windmills here, windmills constructed by some New Age writers and their debunkers, but certainly not by scholarly near-death researchers.

Nevertheless, let me acknowledge that, even if there are only a few near-death researchers who believe that NDEs provide evidence for survival, Augustine may still be correct in his suspicion that "neardeath researchers generally disregard hallucinatory NDEs while searching for cases of veridical paranormal perception." Regardless of their assessment of the evidence to date, it may be true that neardeath researchers have neglected hallucinatory features of NDEs and focused instead on the more problematic features that suggest a disconnect between mind and body. Researchers would do well to heed Augustine's warning and examine whether their interests bias the types of data they collect.

Augustine suggests that personal experience with hospitals and media portrayals make it easier for people to imagine what went on around them when they were ostensibly unconscious. He quotes 
Tillman Rodabaugh that accurate descriptions would be likely: "For example, isn't it easy to guess that a physician will wear his greens in surgery?" (Rodabaugh, 1985, p. 109). But this yet another windmill: no near-death researcher has cited such "high-probability" guesses as evidence of veridical perception. Indeed, it is only descriptions of extremely low antecedent probability that have been cited, such as one woman's accurate description of the plaid shoelaces on a nurse participating in her resuscitation (Ring and Lawrence, 1993), or one man's accurate description of his cardiac surgeon during his openheart surgery "flapping his arms as if trying to fly" (Cook, Greyson, and Stevenson, 1998, p. 399), hardly the type of behavior typically shown in media portrayals of open-heart surgery. Both of these examples, incidentally, were corroborated by independent interviews with the doctors and nurses involved. In a specific test of ability of patients to imagine accurate resuscitation scenarios, Michael Sabom (1981, 1982) found NDErs' descriptions of their resuscitations to be highly accurate with specific veridical details, whereas those of resuscitated patients who did not report NDEs but were asked to imagine what their resuscitations must have looked like were vague and contained erroneous specifics. So the data contradict Augustine's assertion that personal experience with hospitals and media portrayals make it easy for people to imagine what went on around them when they were ostensibly unconscious.

Augustine appropriately raises the question of whether NDErs' accounts accurately reflect what they experienced. Their fidelity to the original experience is certainly not a given. But his leap from that reasonable question to his claim that these accounts were embellished or otherwise distorted is precisely the kind of untested assumption of which he accuses near-death researchers. Augustine counters what he regards as near-death researchers' blind trust in NDErs' veracity with his own blind trust in their mendacity, an equally unscientific position.

I agree with Augustine that the NDE research done so far on the question of survival is not compelling. However, mere speculation about alternative explanations of these data is even less compelling. David Lester, himself a disbeliever in survival, chided his fellow skeptics: "Although the research conducted by those who argue that NDEs are evidence for life after death is often methodologically poor, the critics of this position have published no research" (Lester, 2003, p. 255). Simply pointing out that investigators could have asked 
experiencers leading questions or that corroborating witnesses could have lied or that NDErs could have remembered incorrectly is not presenting evidence that any of those things actually did happen. Any investigator in any field can always be accused of fraud, but such an accusation without supporting evidence is the weakest of arguments. As Henry Sidgwick said 125 years ago in his President's Address at the first meeting of the Society for Psychical Research, "We have done all we can when the critic has nothing left to allege except that the investigator is in [on] the trick. But when he has nothing else left to allege he will allege that" $(1882$, p. 12).

Augustine raised the specific question of embellishment of NDE accounts over years: "Rense Lange, Greyson, and James Houran have even found suggestive statistical evidence for embellishment. . . [T] longer the delay between having the experience and reporting it, the more intense the NDE that was reported. . . . The authors suggested longitudinal studies to definitively determine the extent of embellishment in NDEs."

This is a valid question to raise, but it has now been answered, although, in fairness to Augustine, he would have no way of knowing this. Greyson (2007) recently tracked down 72 NDErs who had completed the NDE Scale in the 1980s and had them complete the scale again, without referring to the original scale administration. Scores did not change significantly on the total NDE Scale, on any of its 4 factors, or on any of its 16 items. Correlation coefficients between scores on the two administrations were significant at $p<.001$ for the total NDE Scale, for its 4 factors, and for its 16 items. Correlation coefficients between score changes and time elapsed between the two administrations were not significant for the total NDE Scale, for its 4 factors, or for its 16 items. Thus NDE accounts in this group were not embellished over a period of two decades, and the consistency of the accounts did not diminish with increased time.

Augustine also suggests that researchers' questions played a role in shaping NDE reports: "One wonders how much similarity would have been found between individual NDE accounts in the West had these early researchers simply asked their respondents to speak freely about their experiences without steering them in a particular direction by probing for Moody's elements." Again, this is a reasonable question to ask, but it too has now been answered. Geena Athappilly, Greyson, and Stevenson (2006) compared NDE accounts collected in recent years by investigators familiar with Moody's model and narrative 
accounts submitted to researchers by experiencers prior to the publication of Moody's book describing the prototypical NDE model. With the exception of the experience of a tunnel, none of the 15 features Moody described was mentioned more frequently in the recent accounts than it was in the pre-Moody spontaneous narratives. And the tunnel experience has been singled out previously by several independent researchers as being incidental to the NDE on several different empirical and theoretical grounds.

Finally, after critiquing spontaneous case reports of veridical perception, in which we can rarely rule out sensory cues, subliminal perception, memory distortions, and erroneous probability estimates, Augustine reviews controlled studies of veridical perception in NDEs and finds them equally unimpressive. He concludes that not a single case of corroborated veridical perception has been documented after a quarter century of near-death studies. This is a common complaint of debunkers, that "many years of research" has turned up no evidence of survival, as if that represented a huge outlay of resources.

In fact, veridical NDE research has been limited to just five studies with minimal or no funding. Those five studies included a total of only 12 NDEs with out-of-body components: eight in the study by Penny Sartori (2004), four in the study by Sam Parnia and his colleagues (Parnia, Waller, Yeates, and Fenwick, 2001), and none in the studies carried out by Janice Holden and Leroy Joesten (1990), by Madelaine Lawrence (1997), or by Greyson, Holden, and Paul Mounsey (2006). Twelve NDEs with out-of-body components is a rather small sample on which to base a conclusion. I would suggest that this effort is not yet worth abandoning. In fact, I am aware of one international consortium of researchers who are seeking funding for the kind of multicenter study that Augustine suggests may settle the issue one way or another.

Nevertheless, even though the sample size collected so far may be inadequate to justify confidence in Augustine's conclusion, the little evidence we have from these controlled studies points to NDErs being unable to see hidden visual targets. For those researchers who believe that the spontaneous case reports of veridical perception in NDEs are precisely what they purport to be, it is frustrating that the phenomenon has not been replicated under controlled conditions that eliminate sensory cues, control probabilities, and circumvent memory distortions. More than one researcher has attributed this failure to an inherent "trickster" quality to NDEs that teases us with anecdotal 
evidence but hides from the light of controlled scientific research (Hansen, 2001; Moody, 1999; K. Ring, personal communication, August 7, 2006 - though this last source made the suggestion "tongue-in-cheek"). But as intriguing as the trickster hypothesis may be to anthropologists, it is a dead-end for neuroscientists. Researchers need to take seriously a variety of hypotheses to explain this lack of evidence, including the hypothesis that the appearance of veridical perception during NDEs is an artifact of faulty or selective memory and reporting.

I am grateful to Augustine for highlighting some of the weaknesses in this evidence, such as the self-selection and delayed reporting of cases, and for suggesting alternative explanations for some of the data that have been offered as supporting the survival hypothesis. As Harold Widdison reminded us, "Judging each other is not a weakness of any field but a sign of growing maturity. We should question each other's research. Then, if we find weaknesses, we can correct them and do more research. So brick by brick correctly placed, we create a theoretical model that fits and helps to understand near-death phenomena" (Widdison, 2002, p. 285). I hope our field has the growing maturity to learn from critiques such as Augustine's and to respond constructively to their challenges.

\section{References}

Cook, E. W., Greyson, B., and Stevenson, I. (1998). Do any near-death experiences provide evidence for the survival of human personality after death? Relevant features and illustrative case reports. Journal of Scientific Exploration, 12, 377-406.

Greyson, B. (2007). Consistency of near-death experience accounts over two decades: Are reports embellished over time? Resuscitation, 73, 407-411.

Greyson, B., Holden, J. M., and Mounsey, J. P. (2006). Failure to elicit near-death experiences in induced cardiac arrest. Journal of Near-Death Studies, 25, 85-98.

Grosso, M. (1983). Jung, parapsychology, and the near-death experience. Anabiosis: Journal of Near-Death Studies, 3, 3-38.

Hansen, G. P. (2001). The trickster and the paranormal. Philadelphia, PA: Xlibris.

Holden, J. M., and Joesten, L. (2001). Near-death veridicality research in the hospital setting: Problems and promise. Journal of Near-Death Studies, 9, 45-54.

Lawrence, M. (1997). In a world of their own: Experiencing unconsciousness. Westport, CT: Praeger.

Lester, D. (2003). Critics of near-death experiences as evidence for survival: A methodological note [Letter]. Journal of Near-Death Studies, 21, 253-256.

Moody, R. A. (1999). The last laugh: A new philosophy of near-death experiences, apparitions, and the paranormal. Charlottesville, VA: Hampton Roads Publishing.

Parnia, S., Waller, D. G., Yeates, R., and Fenwick, P. (2001). A qualitative and quantitative study of the incidence, features and aetiology of near death experiences in cardiac arrest survivors. Resuscitation, 48, 149-156. 
Ring, K. (1990). Shamanic initiation, imaginal worlds, and life after death. In G. Doore (ed.), What survives? Contemporary explorations of life after death (pp. 204-215). Los Angeles, CA: Tarcher.

Ring, K., and Lawrence, M. (1993). Further evidence for veridical perception during near-death experiences. Journal of Near-Death Studies, 11, 223-229.

Rodabaugh, T. (1985). Near-death experiences: An examination of the supporting data and alternative explanations. Death Studies, 9, 95-113.

Sabom, M. B. (1981). The near-death experience: Myth or reality? A methodological approach. Anabiosis: Journal of Near-Death Studies, 1, 44-56.

Sabom, M. B. (1982). Recollections of death: A medical investigation. New York, NY: Harper and Row.

Sartori, P. (2004). A prospective study of NDEs in an Intensive Therapy Unit. Christian Parapsychologist, 16, 34-40.

Sidgwick, H. (1882). Address by the president at the first general meeting. Proceedings of the Society for Psychical Research, 1, 7-12.

Widdison, H. A. (2002). Book review of Children of the new millennium: Harold Widdison responds [Letter]. Journal of Near-Death Studies, 20, 281-285. 